\title{
Evolución de la terapia antimicrobiana: lo que era, lo que es y lo que será
}

\author{
GUILLERMO ACUÑA L*
}

\section{Evolution of antimicrobial agents therapy: what it was, what it is and will be}

A synthesis of the development of antimicrobials is presented. This includes the ancient period and modern times, before and after the discovery of antibiotics. The explosion in the development of antibiotics and the threats for the future are discussed.

Key words: Antimicrobial agents; History; Development; Research

Esta Conferencia es dictada en honor a dos de los Miembros Honorarios de la Sociedad Chilena de Infectología:

El Dr. Roque Kraljevic Orlandini, pionero de la especialidad en nuestro país, formador de numerosos especialistas y profesor de la Cátedra de Enfermedades Infecciosas de la Universidad de Chile y Pontificia Universidad Católica de Chile. $\mathrm{Su}$ ejemplo debiera motivar a muchos colegas a perfeccionarse en esta disciplina.

El Dr. Antonio del Solar, Internista, maestro de muchas generaciones, quien mostró siempre una gran pasión por la patología infecciosa y en especial por el adecuado manejo de sus armas más eficaces, los antimicrobianos.

Las infecciones han motivado el interés del ser humano desde hace muchos milenios. Inicialmente las infecciones de heridas, producto de guerras, cacerías o accidentes, fueron las infecciones más fácilmente identificables y sobre las cuales se intentó diversas acciones terapéuticas.

\section{En la antiguedad}

Ya en los años 2500 AC en China se describió el uso del moho de la soya para el tratamiento de furúnculos, carbunco y otras infecciones cutáneas. No se ha podido demostrar si en este tipo de productos pudiera haber existido una sustancia tipo penicilina.

En Egipto, también 2500 años AC, se empleaba la mirra para el tratamiento de las heridas. En los años $2000 \mathrm{AC}$ el uso de miel y grasa también, para heridas infectadas y en los años $1500 \mathrm{AC}$ la malaquita y crisocola (ambas con cobre), siem- pre en el manejo de heridas.

En Grecia, 400 AC, Hipócrates describió las propiedades terapéuticas de la mirra.

En Roma, Celsus usó mirra y barbarum (contienen cobre y plomo) para el tratamiento de varios procesos infecciosos.

Todos los compuestos descritos (salvo la miel) son demasiado tóxicos administrados por vía general.

\section{Tiempos modernos; era pre-antimicrobiana}

En 1865, Joseph Lister demostró que el fenol líquido, utilizado para desinfectar instrumental quirúrgico, heridas, incisiones e incluso el aire de pabellones, permitía disminuir la mortalidad de 45 a $15 \%$ en su hospital.

En 1876, Robert Koch aisló el Bacillus anthracis, lo cultivó y al inocularlo en animales reprodujo la enfermedad. Era el inicio de la era bacteriológica.

En 1887, Louis Pasteur, descubrió que bacterias ambientales pueden destruir el $B$. anthracis y que animales infectados con otros microorganismos son resistentes al ántrax. Este fenómeno de interferencia se denominó antibiosis.

En 1898, Rudolph Emmerech aisló la piocianasa bacteriana de Pseudomonas aeruginosa. Se probó en algunos pacientes con éxito relativo pero con mucha toxicidad, continuando su uso hasta 1913.

En esta época se utilizó la optoquina para el tratamiento de la neumonía neumocóccica. En 1917 se abandonó por toxicidad y resistencia; probablemente fuera ésta la primera descripción

\footnotetext{
* Pontificia Universidad Católica de Chile, Clínica las Condes, Hospital del Trabajador de Santiago.

E-mail: gacuna@netline.cl
} 
de toxicidad de un fármaco administado por vía sistémica.

Paul Erlich inició una búsqueda sistemática de una tinción que destruyera las bacterias. El compuesto arsenical 606, arsfenamina, fue efectivo contra el Treponema pallidum. Su efectividad se vio obscurecido por la toxicidad.

\section{Tiempos modernos; era antimicrobiana}

1928, Sir. Alexander Fleming, descubrió la penicilina. Basado en el fenómeno de inhibición del crecimiento de Staphylococcus aureus, en una placa contaminada por Penicillum notatum, este genial investigador fue capaz de aislar un producto que era capaz de inhibir el crecimiento de Streptococcus pneumoniae, Neisseria meningitidis, Neissseria gonorrhoeae y otros estreptococos.

Fleming, además de investigador era un referente en Inglaterra en relación al tratamiento de la lúes; sin embargo, él no consideró la posibilidad de que este producto tuviera acción sobre el treponema ni tampoco consideró la posibilidad del uso sistémico de penicilina. Sus ensayos se limitaron a tratamiento tópicos en piel y ojos. $\mathrm{Su}$ interés se derivó a otro hallazgo suyo, la lisozima, a la que dedicó muchos años de su vida. Otra razón para abandonar la investigación en penicilina fue la rápida inactivación del producto, lo que hacía difícil producir y conservar el principio activo.

En 1928, Gerhard Domagk, demostró que el Prontosil@ (sulfa) inyectado curaba infecciones estreptocóccicas sistémicas. A raíz de este descubrimiento que abrió el manejo clínico de infecciones sistémicas con un antibacteriano, se le otorgó el Premio Nobel en 1939, el cual no pudo recibir hasta 1947, terminada la II Guerra Mundial.

Afortunadamente el interés por la penicilina no murió con el abandono de Fleming, en 1935. El Profesor George Dryer, de la Universidad de Oxford, se interesó en este producto; pensaba que se trataba de un bacteriófago, que infectaba y destruía bacterias, esa era el área de interés de Dryer. Al desechar esta hipótesis, una vez más se perdió el interés en la penicilina; sin embargo, las cepas de Fleming fueron conservadas por una ayudante del Profesor Dryer, la Srta. Campbell Renton, quien las mantuvo vivas.

$\mathrm{Al}$ fallecer Dryer, fue reemplazado en Oxford, por Sir Howard Walter Florey.

Ernst Boris Chain, químico alemán que se incorporara al equipo de Florey, le propuso estudiar las cualidades químicas de la penicilina. Des- cubrieron que no era una enzima (hipótesis de estudio). Lograron estabilizarla, cristalizarla y mostrar que altas dosis en animales de laboratorios no eran tóxicas y que podía recuperarse de la orina de los animales tratados, lo que revelaba una distribución sistémica.

El estudio crítico en que se basa la nueva terapia antimicrobiana, se hizo en 8 ratas, las que fueron inyectadas con dosis letales de Streptococcus. Cuatro de ellas recibieron penicilina y las otras sirvieron de control. Las tratadas sobrevivieron, las ratas control murieron.

El primer paciente tratado por Florey (reportado en 1945) fue un policía londinense, con septicemia estreptoccócica; inicialmente hubo una buena respuesta clínica, pero finalmente murió por falta de producto.

A pesar de la insistencia de Chain, Florey no patentó el producto.

La producción industrial de penicilina se desarrolló con la participación norteamericana. El Penicillum es un hongo muy aerofílico, crece en la superficie del caldo de cultivo. El uso de la fermentación en profundidad, utilizando grandes contenedores desarrollados en la industria cervecera, permitió producir cantidades industriales del fármaco, para su utilización clínica.

En 1945, Fleming, Florey y Chain, recibieron el premio Nobel.

En su discurso de aceptación del premio Nobel, Fleming hizo una advertencia:

"Pero quiero dar una advertencia, la penicilina aparece como no-tóxica, de modo que no hay preocupación con sobredosis e intoxicar al paciente. Sin embargo, puede existir el peligro de sub-dosificación. No es difícil conseguir microorganismos resistentes a penicilina en el laboratorio exponiéndolos a concentraciones no letales y lo mismo puede pasar en el organismo." Sir Alexander Fleming (Discurso de recepción del premio Nobel, 1945).

En Chile, a fines de los cuarenta llegaron pequeñas cantidades de penicilina; para su adecuada indicación y distribución se creó la " $\mathrm{Co}$ misión de la Penicilina”, presidida por el Dr. Abraham Horwitz e integrada entre otros por el Dr. Kraljevic.

El uso de terapia antimicrobiana se inició en esta época en Chile, reportándose en la literatura su indicación en los primeros casos de meningitis meningocóccica, (1942), por el grupo liderado por el Dr. Kraljevic.

Él mismo asumió la Dirección Médica de Laboratorios Pfizer en Chile, y desde aquí se realizaron estudios clínicos que hoy consideraríamos de etapas II y III, con protocolos diseñados y 
conducidos en Chile.

El progreso de la era antimicrobiana se aceleró; en 1940 Ron Waksman aisló actinomicina, en 1942 la estreptotricina y en 1944 la estreptomicina. El bautizó estos compuestos como antibióticos. La estreptomicina demostró alta potencia sobre microorganismos Gram negativos y actividad anti Mycobacterium. El Dr. Waksman obtuvo el premio Nobel en 1952.

De ahí en adelante se desarrolló un numeroso grupo de compuestos antimicrobianos.

Desde los años 80 la industria farmacéutica se dedicó a modificar moléculas ya conocidas, con el objeto de cambiar el espectro de acción, las cualidades farmacológicas (absorción oral, vida media más prolongada, mejor distribución, etc).

Las modificaciones realizadas a la molécula de penicilina son notables, logrando compuestos resistentes a la acción de $\beta$-lactamasas de especies Gram positivas, actividad amplia sobre enterobacterias y luego Pseudomonas, etc. Algo similar se produjo con grupos como cefalosporinas y cefamecinas, quinolonas, macrólidos, etc.

Ya en 1939, Abraham y Chain, describieron la primera $\beta$-lactamasa; sin embargo, su importancia no se reconoció hasta la aparición de Staphylococcus resistentes a penicilina, lo que ocurrió en los primeros años del uso masivo de este producto.

El fenómeno de resistencia se extendió a otros antimicrobianos como sulfas, tetraciclinas, cloranfenicol y aminoglucósidos. Desgraciadamente esta respuesta biológica a la presión por el uso de antimicrobianos es algo que persiste y que en la actualidad nos ha llevado a observar como han aparecido organismos como Mycobacterium tuberculosis, Enterococcus faecium, Acinetobacter spp y Pseudomonas spp resistentes a todos los antimicrobianos disponibles en el arsenal terapéutico.

El estado actual de la terapia antimicrobiana, es que existiendo una gran variedad de productos, tenemos aún dificultades serias para el manejo de infecciones bacterianas producidas por microorganismos resistentes a los productos disponibles, necesitándose nuevos compuestos que sean capaces de sobrepasar las barreras de resistencia a los antimicrobianos que nosotros mismos hemos ayudado a construir.

\section{Futuro}

La empresa farmacéutica ha implementado varias vías de desarrollo de nuevos compuestos.
La vía empírica: que implica el hallazgo de compuestos por screening de diversos candidatos, conociendo la relación estructura / actividad. Este método, refinamiento del empleado por Paul Erlich el siglo pasado, es en general usado actualmente con un grupo pre-seleccionado de compuestos que teóricamente deben tener una actividad determinada, para luego iniciar pruebas farmacocinéticas y de seguridad.

La vía racional: requiere la definición de nuevos blancos (enzimas o genes responsables de funciones celulares cruciales) y el desarrollo de un inhibidor o bloqueador de dicha función o gen. Una variante es usar un modelo físico basado en cristolagrafía de rayos $\mathrm{X}$, espectrografía de resonancia magnética con el apoyo de computadores.

Entre las vías de desarrollo futuro podemos destacar:

- Desarrollo de nuevos antimicrobianos: las oxazolidinonas (p ej linezolid) son el ejemplo más reciente del exitoso desarrollo de un nuevo grupo de antimicrobianos, el primero después de treinta años.

- Cambios químicos de agentes actuales: un producto en desarrollo actual, la tigacilina, es un buen ejemplo de esto, es una tetraciclina modificada que previene las principales causas de resistencia como son la protección del ribosoma bacteriano por moléculas proteicas, (tetM-tetO) y los mecanismos de eflujo. El resultado es una molécula con espectro anti Gram positivos, Gram negativos [incluyendo Acinetobacter baumannii pero no Pseudomonas] y especies anaerobias.

- Desarrollo de potenciadores: los ejemplos más notables son los inhibidores de $\beta$-lactamasas; sin embargo, este campo sigue en desarrollo buscando inhibidores de los genes vanH, vanA y vanX, que permitirán recuperar la actividad de vancomicina.

- Inhibidores de factores de virulencia y patogénesis: La adherencia a receptores celulares es vital para la infectividad. Por ejemplo, se han desarrollado oligosacáridos con actividad específica de inhibición de adherencia de Helicobacter pylori. También se han desarrollado inhibidores de los genes reguladores de exoproteinas estafilocóccicas.

- Antinucleótidos antisentido: son oligonucleótidos que se unen a segmentos críticos del ADN o ARN bacteriano, comportándose como molécula anti-sentido de la replicación o metabolismo proteico. También es utilizable en antivirales. La obtención de elementos específicos y químicamente estables ha sido el mayor obstáculo. 


\section{Amenazas para el futuro}

Varias compañías han anunciado el retiro o disminución de la investigación en antibacterianos (Aventis, Bristol Myers Squibb, Lilly, GlaxoSmithKline, Procter \& Gamble; Roche y Wyeth). En el año 2002, de 89 nuevos medicamentos aprobados por la FDA, no se aprobó fármaco antibacteriano alguno.

El otro dato inquietante es que de 400 nuevas moléculas en desarrollo por los principales laboratorios internacionales, sólo 5 son antibacterianos.

Las razones de esto pueden ser múltiples, incluyendo el efecto de la rápida perdida de los derechos de patente, la actividad de las copias genéricas y el hecho que la industria ha tornado su interés a productos para el uso crónico como son los problemas metabólicos, cardiovasculares, reumatológicos etc. El monto de la inversión para el desarrollo de un nuevo producto y el riesgo de que éste no sea exitoso es tan grande, que pocas empresas están dispuestas a invertir en el área de antibacterianos con el peligro cierto de que si el nivel de resistencia a antimicrobianos sigue incrementándose, estaremos en peligro de volver a las condiciones previas al desarrollo de antimicrobianos.

\section{Conclusiones}

La terapia antimicrobiana se ha desarrollado en un periodo breve en la historia de la humanidad.

A pesar de esto, gracias al ingenio del hombre y el rápido avance de la ciencia y la tecnología, se consiguió en poco tiempo el desarrollo de un importante número de diversos grupos de antimicrobianos que cubren el espectro de la flora bacteriana patógena. Sin embargo, la lucha contra un grupo de organismos que nos precedieron en la evolución por millones de años no ha sido fácil, y estos organismos tienen la suficiente versatilidad evolutiva para responder con diversos mecanismos de resistencia que van haciendo ineficaz la acción del antibacteriano.

El uso prudente y sin triunfalismos de los antimicrobianos, tal como nos ha sido señalado por nuestros maestros, es esencial para la mantención del poder terapéutico de este importante grupo de fármacos.

\section{Resumen}

Se presenta una síntesis del desarrollo de los antimicrobianos, abarcando la antigüedad y los tiempos modernos, incluyendo la era preantibiótica, el periodo del explosivo desarrollo de antibióticos y el futuro en el cual se plantea los riesgos del incremento de la resistencia y el menor interés de la industria en invertir en la investigación de nuevos compuestos.

\section{Bibliografía}

1.- Moore H F, Chesney A M. A study of ethylydrocupreine (optochin) in the treatment of acute lobar pneumonia. Arch Intern Med 1917; 19: 611.

2.- Wilson D. In search of Penicillin (New York: Alfred A. Knopf, 1976.

3.- Fleming A. On the bacterial action of cultures of Penicillium, with special reference to their use in isolation of H.influenzae. $\mathrm{Br} \mathrm{J}$ Exper Pathol 10 (1929):226

4.- Abraham E P, Chain E. An enzyme from bacteria able to destroy penicillin. (Letter) Nature 1940; 146: 837.

5.- Chain, E. Penicillin as a chemotherapeutic agent. Lancet 2 (1940): 226

6.- Acuña G. Descubrimiento de la penicilina, un hito en la Medicina. Rev Médica Clínica las Condes.2002. Vol 13: 1.

7.- Friedman M, Friedland G. Alexander Fleming and Antibiotics. In Medicine's 10 Greatest Discoveries. Yale University Press, New Haven, 1998: 168-91.

8.- Silver L, Bostian K. Screening of natural products for antimicrobial agents. Eur J Clin Microbiol Infect Dis 1990; 9: 455-61.

9.- Allan J D, Eliopoulos G M, Moellering R C Jr. Antibiotics: future directions by understanding structurefunction relationships. In Sande M, Root RK, Eds. Treatment of Serious Infections in the 1990s. New Surgical and Medical Approaches in Infectious Diseases. New York: Churchill Livingstone 1987; 6: 263-84.

10.- Moellering R C Jr. The relation between structure and activity of new antimicrobial agents. In Sande M, Root RK, Eds. Treatment of Serious Infections in the 1990s. New York: Churchill Livingstone 1992; 9: 114.

11.- Domagala J M. Structure-activity and structure-side effect relationships for the quinolone antibacterials. J Antimicrob Chemother 1994; 33: 685-706.

12.- Billstein S A. How the pharmaceutical industry brings an antibiotic drug to market in the United States. Antimicrob Agents Chemother 1994; 38: 2679-82.

13. Moellering R C Jr. Past, present and future of antimicrobial agents. Am J Med 1995; 99(6A) Suppl 1. Dec 29: S11-8. 